\title{
A Hybrid Renewable Energy Model For Medina City of Saudi Arabia Using Integer Linear Programming
}

\author{
Adel S. Bahakeem \\ Jubail Industrial College, Jubail Industrial City 31961, KSA
}

\begin{abstract}
This paper describes modelling of hybrid renewable energy systems using a mathematical approach. This approach chiefly emphasizes on integratingtwo renewable energy sources viz the solar energy and wind energy. Itfocuses the need for hybrid power generationand estimationof their annual power generation.For the purpose of analysis a suitable location, Medina city in Saudi Arabia is being considered. This approach involves the concept, lossof power supply probability to minimize the initial capital investment. A Feasible solution is being arrived in presenting the integration of these renewable energy sources in a complementary way which is a technically feasible and financially viable. The conclusion of proposed method can be directly adapted, since the numbers of units are pure integer numbers. As a consequence determining the optimal energy source to be installed leads to determine the required number of units from each source. This has been modelled as an integer linear programming problem where the decision variables should be pure integer numbers. With minimal cost to get maximumeconomical power output from hybrid renewable source 5PV panel and 25 Wind Turbine can be used.
\end{abstract}

Key words:Integer Linear Programming, Hybrid Energy, PV system, Wind Turbine, Graphical Analysis

\section{Introduction}

The Kingdom of Saudi Arabia (KSA) is one of the most prominent countries in the Middle East with a population of 25.7 million with a total area of 2.2 million square kilometres. The country lies between latitude of $17.5^{\circ} \mathrm{N}$ and $31^{\circ} \mathrm{N}$ and longitude of $36.6^{\circ} \mathrm{E}$ and $50{ }^{\circ} \mathrm{E}$. It has about 260 billion barrels of oil reserves, comprising about one-fifth of the world's proven total petroleum reserves.In the wake of the growing importance of the building sector in terms of energy consumption and carbon emissions, it is essential for the KSA to shift towards energy efficient technologies [1]. KSA receives one of the highest solar irradiation intensity on the earth. The region is attracting the attention of people to harvest this solar energy for their nations.In this context, this paper explores the need of Hybrid renewable energy bypromoting their implementation in the country. The dependency of energy generation on the Hybrid renewable energy like solar and wind energy is unpredictable because the energy generation would merely depend on the weather and climate of the chosen location with in combination with load duration of the location[2].The optimum sizing of the number of photovoltaic (PV) panels and the wind generators is very much necessary to achieve an optimized hybrid system. The utilization of the efficient optimized hybrid energy system would reduce the costof per kilo watt hour (unit) energy generated further ensuringreliability of the hybrid energy system. Various optimization techniques such as the mathematical programming, graphical analysis and iterativemodelling have been recommended by researchers. A graphical construction technique for figuring the optimum combination of battery and PV array in a hybrid Solar-wind system has been presented by Borowy and Salameh1996[2]. The system operation is simulated for variouscombinations of PV array and battery sizes and the loss ofpower supply probability (LPSP).

The land elevation in the KSA varies between 0 and $2600 \mathrm{~m}$ above the mean sea level. The East and the West coastsof theKSA are located on the Arabian Gulf and Red Sea, respectively. The vast open landexperiences high intensities of solar radiation and long hours of sunshine duration. Solar energy-based appliances are being used at the Royal Commission of Yanbu and Jubail. The world's first and the largest gridconnected PV facility was developedand tested at Solar Village situated on the outskirt of Riyadh, the capital city of SaudiArabia.

This paper analyses the benefit of a Hybrid power generation system.In regards to wind,offshore-wind energy of the mainland coasts of Saudi Arabia is more useful, than the known onshore windresources. The study ofwind speed data on an offshoremeteorological station to find the annual variation of wind speed, frequency distribution, energy yield and consequent opportunity for reduction in emission of greenhouse gases. The annual mean wind measured at Abu Ali Island, theoffshore location, was $5.43 \mathrm{~m} / \mathrm{s}$. which is larger than the $4.9 \mathrm{~m} / \mathrm{s}$ measured over the sameperiod at Abu Kharuf, the nearby inland location [3]. Larger wind speeds were found in wintermonths than in summer months at both locations. The prevailingwind direction was found to be North $(\mathrm{N})$, North West (NW) and North East (NE). In terms of solar energy, the KSA is one of the richest countries in the world as it has 3245 sunshine hours per year with an annual solar radiation more than $2.0 \mathrm{MWh} / \mathrm{m}^{2}$ per year [4]on horizontal surface. 


\section{Data Collection}

The aim of this study is to chiefly emphasize the need of hybrid energy systems keeping in view the depletion of natural resources in the country and to reduce emission of green house gases. The Medina city of KSA havinglatitude of 24.55 degrees and longitude 39.72 degrees is chosen for the purpose of analysis [4].

The approach of analysis is a mathematical technique called integer linear programming which is composed of integer units. The approach clearly shows $\mathrm{N}_{1}$, number of units PV panels needed to combine with $\mathrm{N}_{2}$ number of units of the wind energy to arrive at afeasible solution.

S Rehmanet all [4], gave the Global solar radiation data for Medina city is $2.32 \mathrm{MWh} / \mathrm{m}^{2}$-yr. The wind speed for medina city is 3 meters per second according to [5].

\section{Estimation of Annual Photovoltaic Energy for Medina City}

According to the manufacturers data specifications the energy produced by a PV panel over a period of timedepends mainly on someimportant factors [6] which include.

1. Type of the cell, whetherMônocrystalline or thin film

2. Maximum power rating $P_{\max }$

3. Solarirradiance of thelocation.

4. Season and hour of the day.

5. Shadowing obstructions if any

6. Climatic conditions of the location

7. Inclination of the panel etc.

The global formula used for estimation of the electricity generated in output of a photovoltaic system [6] is $\mathrm{E}=\mathrm{A} \times \mathrm{r} \times \mathrm{H} \times \mathrm{PR}$

where

$\mathrm{E}=$ Energy in kilo watt hours $(\mathrm{kWh})$

$\mathrm{A}=$ Area of the PV panel in $\left(\mathrm{m}^{2}\right)$.

$\mathrm{r}=\mathrm{PV}$ panel yield in percentage. (It is calculated by electrical power (in $\mathrm{kWp}$ ) of one PV

panel divided by its area)

$\mathrm{H}=$ annual average solar radiation on tilted panel (shadings not included)

$\mathrm{PR}=$ performance ratio is the coefficient for losses lies between 0.5 to 0.9 , default value $=0.75$ ).

We used equation (1) to estimate the Electrical Power of one PV paneltaking following values

$\mathrm{A}=1.6 \mathrm{~m}^{2}$.

$\mathrm{r}$ for $250 \mathrm{~W}$ peak power with $1.6 \mathrm{~m}^{2}$ area is $15.6 \%$.

$\mathrm{H}$ for Medina City $=6356 \mathrm{w} / \mathrm{m}^{2}[7]$

$\mathrm{PR}=0.75$

Substituting all these values in equation (1) we get

$$
\mathrm{E}_{\mathrm{ph}}=118984 \mathrm{~W} / \text { year or } 119 \mathrm{kWh} / \text { year }
$$

The annual power produced by one PV panelcan be estimated according to[8],taking into consideration that one watt of peak power produces an annual energy of about $2 \mathrm{kWh}[9]$.

The solar energy generated by one silicon crystalline panelof area $1.6 \mathrm{~m}^{2}$ as per the equation (1), can be estimated to have a peak power of $119 \mathrm{kWh}$.So a single PV panel produces about $238 \mathrm{kWh} / \mathrm{year}$.

\section{Estimation of Annual Wind Turbine Energy}

The power generated by a wind turbine can be estimated by using the following expression[10]

$$
\mathrm{P}_{\text {Turbine }}=\frac{1}{2} \mathrm{C}_{\mathrm{p}} \rho \pi \mathrm{R}^{2} \mathrm{~V}^{3}(2)
$$

Where,

$\mathrm{Cp}$ is the operating efficiency factor in percentage

$\rho$ the density of air at sea level, which is about $1.2 \mathrm{~kg} / \mathrm{m}^{3}$.

$\mathrm{R}$ is the blade radius in meters

$\mathrm{V}$ is the wind speed in $\mathrm{m} / \mathrm{sec}$.

The performances of the wind turbine may be improved by increasing the wind speed by changing the height.

Speed of wind at height $\mathrm{h}$ is given by, $\mathrm{V}=\mathrm{V}_{\mathrm{o}} \times\left(\mathrm{h} / \mathrm{h}_{0}\right)^{\alpha}(3)$

Where,

$\mathrm{V}_{0}$ - the wind speed at the reference height $(10 \mathrm{~m})$.

h- Hub height

$\mathrm{h}_{0}$-the reference height which is usually $10 \mathrm{~m}$

$\alpha$-the power law exponent usually taken as 1/7. 
The wind speed measured in the Medina city with latitude 24.55 degreeand longitude 39.72 degree at height 10 meters after referring to 101,407 records as $3 \mathrm{~m} / \mathrm{sec}$ [4].

The wind speed is calculated at elevated height of $30 \mathrm{~m}$ using equation (3) and taking blade diameter of wind turbine as $2 \mathrm{~m}$ and at operating efficiency of $20 \%$. At this height its value is $3.5 \mathrm{~m} / \mathrm{s}$.

The estimated power of a wind turbine is nearly 16 watt, taking above values and using equation (2)

If we assume that wind turbine produces expected power of 1625 hours per year then the annual wind energy (Ew) is obtained as $26 \mathrm{KWh} /$ year.

In the location where the measures have been obtained, the average value of the wind speed over 27 years is about $2.5 \mathrm{~m} / \mathrm{s}$ which means that the site is not very interesting for wind turbine exploitation. Nevertheless, there are some elevated site which are more windy.

Thus, if we consider small wind turbine with a blade diameter of $2.5 \mathrm{~m}$ and an operating efficiency factor $\mathrm{Cp}=20 \%$ at a reference average wind speed of $3.9 \mathrm{~m} / \mathrm{sec}$, then elevated only at $35 \mathrm{~m}$ height, we obtain a wind speed of about $4.66 \mathrm{~m} / \mathrm{s}$.

This gives an estimated power $\left(\mathrm{P}_{\text {Turbine }}\right)$ )f about60 Watts. If we assume that the wind turbine produces the expected power of 1625 hours per year, then it would produce about $97 \mathrm{kWh} /$ year renewable wind energy(Ew).

\section{Modelling Hybrid Systems in Terms of Integer Linear Programming}

The problem of optimal reparation of renewable energies can be fixed asfollows.

Consider some renewable energy sources such as: PV panel with unit cost $\mathrm{C}_{1}$; Wind turbine with unit $\operatorname{cost} \mathrm{C}_{2}$ and the demand of energy (D).

The problem can be formulated as a linear programming [8] if there are two or more constraints. But since the energy of each source is constituted from specified units, this leads to add additional constraints on the decision variables that should be pure integer numbers.

If we consider hybrid model of two renewable energy sources the solar energy and wind energy. The problem consists of optimizing the number of PV panels $\left(\mathrm{N}_{1}\right)$ and wind turbines units $\left(\mathrm{N}_{2}\right)$ for desired demand of energy.

Therefore, the problem can be converted into an optimization program known as integer linear programming problem that requires pure integer solutions for decision variables $\mathrm{N}_{1}$ and $\mathrm{N}_{2}$.

An initial general formulation consists of minimizing a cost function $\left(Z_{T}\right)$ while satisfying the demand (D). If the unit costs of each renewable unit is $\mathrm{C}_{\mathrm{i}}$ and its annual production is $\mathrm{E}_{\mathrm{i}}$. The problem can be expressed as follows:

$$
\begin{gathered}
\min \mathrm{Z}_{\mathrm{T}}=\sum_{1}^{\mathrm{n}} \mathrm{C}_{\mathrm{i}} \mathrm{N}_{\mathrm{i}} \\
\mathrm{D}=\sum_{1}^{\mathrm{n}} \mathrm{E}_{\mathrm{i}} \mathrm{N}_{\mathrm{i}}
\end{gathered}
$$

$\mathrm{N}_{\mathrm{i}} \geq 0$

$\mathrm{N}_{\mathrm{i}}$ integers

In fact the integer linear programming problems are more difficult than the linear programming problems. So to over on it, the branch and bond technique [11] is being used to solve it in parts.

For simpler case with two decision variables, graphical representation can help to analyze and solve the problem if a solution exists.

\section{Case Study}

In our study we will consider the example of a small PV/Wind hybrid system. The estimated energy produced by a PV panel (one unit) is $\mathrm{E}_{\mathrm{ph}}=119 \mathrm{kWh} /$ year and the estimated energy produced by a wind turbine (one unit) is $\mathrm{E}_{\mathrm{w}}=97 \mathrm{kWh} /$ year

+If we assume a cost of $4 \$$ per Watt of peak power, then the unit cost of a PV panel is around $\mathrm{C}_{1}=238 \$$.

On the other hand, the cost of the of wind turbine can be estimated at about $\mathrm{C}_{2}=100 \$$

For simplicity, we may only consider in this analysis the investment for capital cost of the hybrid system which may involve the number of PV panels $\left(\mathrm{N}_{1}\right)$ and the numberof wind turbines $\left(\mathrm{N}_{2}\right)$. This capital cost which is the objective function has to be minimized,

i.e. $\min \mathrm{Z}_{\mathrm{T}}(\$)=\mathrm{C}_{1} \times \mathrm{N}_{1}+\mathrm{C}_{2} \times \mathrm{N}_{2}(4)$

If we assume an electrical demand $\mathrm{D}(\mathrm{kWh} / \mathrm{year})$, and to meet this demand, we need to use a certain number of PV panels and a certain number of wind turbines.

This leads to satisfy the following constraint:

$\mathrm{E}_{\mathrm{ph}} \times \mathrm{N}_{1}+\mathrm{E}_{\mathrm{w}} \times \mathrm{N}_{2}=\mathrm{D}(\mathrm{kWh} /$ year) (5) 
In integer linear programming problems, it may be difficult to find out a feasible solution that meets this equality constraint. So, one need to extend the field of feasible solutions by replacing the equality (5) by the inequality constraint such as

$\mathrm{E}_{\mathrm{ph}} \times \mathrm{N}_{1}+\mathrm{E}_{\mathrm{w}} \times \mathrm{N}_{2} \geq \mathrm{D}(\mathrm{kWh} /$ year $)(6)$

Let's assume $\mathrm{C}_{1}=238 \$$ and $\mathrm{C}_{2}=100 \$$,

\section{Case Analysis}

then the objective function $\mathrm{Z}_{\mathrm{T}}$ can be expressed as follows:

$\min Z_{\mathrm{T}}=238 \times \mathrm{N}_{1}+100 \times \mathrm{N}_{2} \ldots \ldots \ldots \ldots(7)$

Let's assume $\mathrm{E}_{\mathrm{ph}}=119 \mathrm{kWh} /$ year and $\mathrm{E}_{\mathrm{w}}=97 \mathrm{kWh} /$ year and an electrical demand $\mathrm{D}$ of about 3020 $\mathrm{kWh} /$ year. Thus, the problem can be expressed as a pure integer linear programming problems as follows:

$\min Z_{\mathrm{T}}=238 \mathrm{~N}_{1}+100 \mathrm{~N}_{2}$

Subject to1 $19 \mathrm{~N}_{1}+97 \mathrm{~N}_{2}=3020$

$\mathrm{N}_{1}, \mathrm{~N}_{2} \geq 0$

$\mathrm{N}_{1}, \mathrm{~N}_{2}$ integers

$\left(\mathrm{N}_{2}\right)$.

The solution gives an objective function value as $3690 \$$ with $5 \mathrm{PV}$ panel $\left(\mathrm{N}_{1}\right)$ and 25 Wind Turbines

The graphical analysis is presented below, where $X$ axis represents $N_{1}$ and $Y$ axis represent $N_{2}$.

The graph being plotted between objective function $\mathrm{Z}$ (Eq. 7) and equality constraint D (Eq. 8) for different value of $Z$. We need to find the point of intersection between them, where $N_{1}$ and $N_{2}$ should be integers. If there are many points which meet the criteria then we select the points which correspond to minimal value of $Z$.

In the example under consideration the optimal value correspond to point $M$ where $Z=3690 \$$, with $N_{1}=5$ and $\mathrm{N}_{2}=25$, which has been already verified by numerical method.

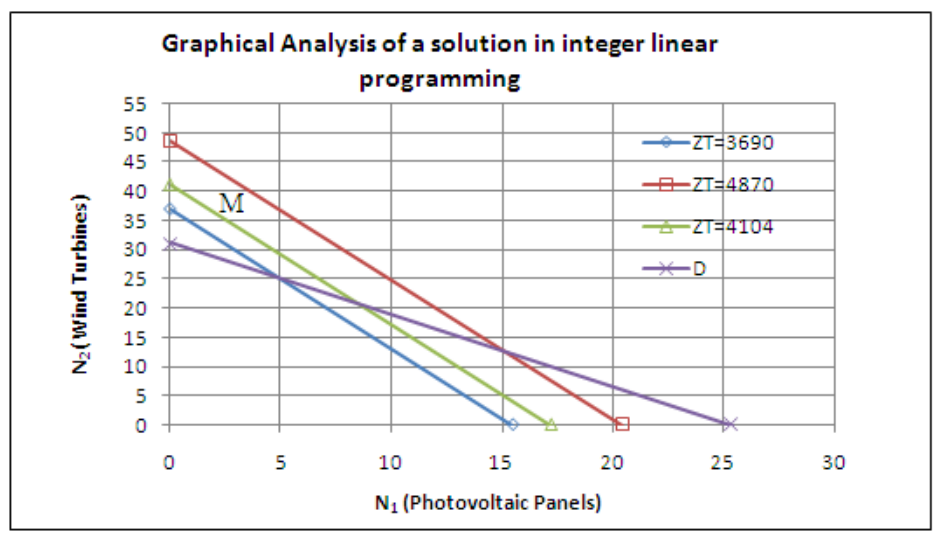

Fig 1

\section{Sensitivity Of Solution}

Let's analyse the sensitivity of the solution of the integer program with the equality constraint (8) with respect to a small change in coefficient characterising the annual wind energy production of a wind turbine unit $\left(\mathrm{E}_{\mathrm{w}}\right)$ as shown in the Table 1

Table 1: Sensitivity of the solution with $\mathbf{E}_{w}$

\begin{tabular}{|c|c|c|c|}
\hline $\begin{array}{c}\text { Annual Wind Energy } \\
\text { Production }\left(\mathrm{E}_{\mathrm{w}}\right)\end{array}$ & $\begin{array}{c}\text { Objective Function } \\
\left(\mathbf{Z}_{\mathrm{T}}, \mathbf{S}\right)\end{array}$ & $\begin{array}{c}\text { PV Panels } \\
\left(\mathbf{N}_{1}\right)\end{array}$ & $\begin{array}{c}\text { Wind Turbine } \\
\left(\mathbf{N}_{2}\right)\end{array}$ \\
\hline 93 & 5008 & 16 & 12 \\
\hline 94 & 4104 & 8 & 22 \\
\hline 95 & 4870 & 15 & 13 \\
\hline 96 & No Solution & -- & -- \\
\hline 97 & 3690 & 5 & 25 \\
\hline
\end{tabular}

It may be notice that integer program is very sensitive, under some circumstances to a small change with respect to an energy unit such as $E_{w}$. It is clear from equation 8 that at $E_{w}=96 \mathrm{kWh} /$ per year the problem has no solution, i. e. graphically there is no interaction between equality constraint and the objective function that corresponds to a point with integer coordinates. 
As a result, the designer should take into consideration, the supervision of the solution as well as the analysis of its sensitivity before deciding to choose theappropriate result.

\section{Conclusion}

In this study we presented optimization of number of energy sources for a hybrid energy system of solar and wind energy for Medina city of Saudi Arabia for economical production of energy. We used integer linear programming technique where decision variables should be pure integers, for optimization and it is verified by graphical method.

In order to obtain optimal energy number of units from each source must be determined. The problem has been modelled as an integer linear programming where decision variables should be pure integer numbers.

The developed model directly links the group of inputs parameter. The parameters depend on wind speed, solar irradiation and day duration etc.

[1]. http://www.Mitsubishi electric solar.com /whysolar/

[2]. Borowy, B. S. and Z. M. Salameh, Methodology for optimally sizing the combination of a battery bank and PV array in a wind/PV hybrid system, Energy conversion, IEEE transactions on energy conversion, 11(2), 1996, 367-375.

[3]. S. Rehman, Offshore Wind Power Assessment on the East Coast of Saudi Arabia, Wind Engineering, 29(5), 2006,409-420.

[4]. Rahman S.,Halawani T.O.and Mohandes M., Wind power cost assessment at twenty locations in the kingdom of Saudi Arabia, Renewable energy, 2, 2003, 573-583

[5]. http://weatherspark.com/averages/32771/Medina-Al-Madinah-Saudi-Arabia

[6]. http://photovoltaic-software.com/PV-solar-energy-calculation.php

[7]. Bahel V.,Srinivasan R. and BakhshH., Solar Radiation for Dhahran, Saudi Arabia. Energy, 11(10), $1986,985-989$.

[8]. A.K.Akella, M.P.Sharma and R.P Saini, 'Optimum Utilization of Renewable Energy Sourcesin a Remote Area, Renewable and Sustainable Energy Reviews, 11(5),2007, 894 - 908.

[9]. http://fr.wikipedia.org/wiki/Module_solaire_photovoltaique

[10]. A. Zaatri. et K. Allab. “Analysis of PV/Wind systems by integer linear programming”. Revue des Energies Renouvelables, 15(1), 2012, $111-120$.

[11]. R.J. Vanderbei, "Integer Programming”, Operational Research and Financial Engineering, Princeton University, April 2009. http://www.princeton.edu/rvdb 